Germany? And what does this case tell us about the nature of science and how we should best study its development?

Nyhart provides some answers. Morphology found niches in other successful disciplines, notably anatomy and scientific zoology. Haeckel stood out partly because of his popular approach and his assertive, indeed bombastic, style, and Gegenbaur developed an exceptionally loyal familylike following among his students, many of whom he placed in foreign universities where they could carry on his research approach and spread his reputation. Finally, we learn that science is done by individuals and embedded in a variety of institutions, in ways that deserve more careful attention, as do the timing of innovations and the generational and power relationships.

We have heard such messages before, but Nyhart is no simple constructionist who thinks that institutions and their context directly cause the science. Rather, the texture of science is rich and varied. We need to explore more aspects, and implicitly all accessible aspects. Along the way, we will even learn much that is instructive for science today, such as the changing relationship of teaching and research, the emphasis on innovation and the competition among epistemological and methodological approaches.

As one of those who challenged Allen's interpretations by calling for a closer study of a wider range of research, I find Nyhart's study exciting, even though she points out that my own emphasis was itself limited in focus and even though she could benefit from a comparison with American and British studies of morphology. She is right: we need a rich diversity of studies in the history of biology, including explorations of odd niches from all sorts of perspectives just as she has persuasively revealed that the science itself is rich and varied.

Jane Maeinschein is in the Departments of Philosophy and Zoology, Arizona State University, Tempe, Arizona 85287-2004, USA.

\title{
White heat of medical practice
}

\section{W. F. Bynum}

\section{Technology in the Hospital: Transforming Patient Care in the Early Twentieth Century. By Joel D. Howell. Johns Hop- kins University Press: 1995. Pp. 341. $\$ 47.50, £ 39.95$.}

ONE modern answer to the old question "Is medicine an art or a science?" might be "Neither, it is a technology". The medicine of the late twentieth century is certainly identified with, and surrounded by, machines, and many of its most dramatic aspects, such as open-heart surgery, nuclear magnetic resonance imaging, haemodialysis or incubators for premature babies, are more the products of technological realizations than of conceptual transformations. Both the power and the cost of medical care have been irrevocably touched by technology. Several of the innovations supposed to reduce costs, such as keyhole surgery with short hospital stays, also depend on recent and promised future technology.

If technology is simultaneously one of medicine's problems and one of its solutions, it is unlikely to disappear from the medical scene. It is therefore surprising that historians of technology and historians of medicine have generally had so little to say to each other. So Joel Howell's monograph is to be welcomed as a study that takes as its fundamental theme the birth of the modern technologically orientated hospital. Take away hospitals, and most of the really expensive equipment of contemporary medical care would disappear. Why and how did these institutions respond to the lure of the machine? Did it make any difference to their patients?

Howell's study is rooted in the patient records of two particular institutions, the Pennsylvania Hospital in Philadelphia and the New York Hospital in New York City, between 1900 and 1925. His analysis of a statistically significant sample of these records allows him to ask several questions about the nature of hospital medical practice in these decades, which, he convincingly argues, coincide with fundamental transformations. The patient records bear eloquent testimony to change. They more than double in median length, and, more importantly, increase by more than five times in the average daily space a record occupies. This discrepancy highlights the reduced average hospital stay, a result heavily influenced by the coming of routine tonsillectomies. In 1900, 2 per cent of patients admitted to the Pennsylvania Hospital were suffering from diseases of the tonsils; in 1925, more than a quarter were. Similar figures obtain for the New York Hospital. Tonsillitis became the most common hospital disease, and the operation by far the most frequent surgical procedure. It first brought children into general hospitals as an ordinary occurrence, almost as a childhood rite of passage.

Howell's quantification of the ton- sillitis phenomenon will probably come as no surprise to many readers with early memories of going under from ether or of ice-cream after surgery. It is almost a byway for Howell, because these children often generated no laboratory tests, such as a urinalysis (almost routine protocol by the end of his period), blood counts (common but still used selectively), bacteriological studies or X-ray examinations. The records of other hospital patients, however, contain the results of these and similar investigations with increasing frequency; often, too, data such as body temperature or pulse rate were collected serially and represented graphically. Blood counts became important for the diagnosis of typhoid fever or the prognosis of pneumonia, and following the discovery of insulin in 1922, the measurement of urinary sugar took on new significance. Printed forms helped to standardize the collection and reporting of data, and the records themselves began to lose the narrative structure that earlier characterized them.

Donating diagnostic blood from a vein, fingertip or ear lobe was a new experience for patients, but nothing captured the public's imagination quite like the X-ray, discovered exactly a century ago and used in medicine within weeks. Howell offers a thoughtful analysis of the assimilation of the X-ray into popular American culture as well as the professional implications of such questions as who pays for, takes and interprets the image. (One early specialist charged less 
simply having to take the patient to and from the equipment created new logistical problems within the hospital.

Howell is neither a technological apologist nor a wistful romantic. Technology changed the nature of the hospital during those decades, adding to its costs and making the surroundings less domestic and familiar. In many instances it changed neither the diagnosis nor the treatment the patient received, but sometimes it could, as when acute appendicitis was part of the differential diagnosis and when white blood cell counts mattered. Analysing a large random sample forces Howell to look at the ordinary, and it is at this level that his book is both intriguing and frustrating. Because his hospitals sometimes responded differently to various new technologies, he is acutely aware of the danger of generalizing from only two institutions. His original project aimed to compare the United Kingdom and the United States; the United
Kingdom is now reserved for a second volume and various US issues - about costs, or the development of paramedical groups, for example - are only cursorily examined. We are shown how the principles of accountancy began to influence hospital finance (the managerial revolution is of long duration), but the counterintuitive revelation that employment costs apparently became less important between 1898 and 1920 (in one hospital, at least) passes without comment.

In his conclusion, Howell relates his historical research to contemporary ethical and economic debates. These lessons are not terribly surprising, but his early twentieth-century portrait is fresh and important, as an analysis of medical practice just coming to grips with the technological world.

W. F. Bynum is at the Wellcome Institute for the History of Medicine, 183 Euston Road, London NW1 2BN, UK.

\section{The shape of things to come}

Ziauddin Sardar

Visions of the Future: The Distant Past, Yesterday, Today and Tomorrow. By Robert Heilbroner. Oxford University Press: 1995 . Pp. 133. \$19.95.

The End of the Future: The Waning of the High-Tech World. By Jean Gimpel. Adamantine: 1995. Pp. 125. £32.50 (hbk); $£ 14.95$ (pbk).

THINKING about the future is a tricky and hazardous business. Tricky because our conventional way of thinking does not normally incorporate the future - we consciously have to strive to imagine what the future may hold, what anticipated and unexpected possibilities lurk on the distant horizon. Hazardous because the probability of getting one's forecasts wrong is very high.

It is not surprising then that both Robert Heilbroner and Jean Gimpel are rather cautious about making any predictions. Heilbroner is concerned chiefly with the way we think about the future and how this thinking has itself changed. Gimpel, on the other hand, focuses largely on the failures, unfulfilled promises and our misplaced optimism that technology would usher in a more humane and sane future. Both are economical with their analysis but nevertheless provide a punchy and thought-provoking examination of our inability to comprehend the future.

Heilbroner takes us through the history of humanity, as seen from the perspective of the West, at an exhilarating pace. The distant past, covering 150,000 years to yesterday, is marked by a wide range of diversity in all spheres of human existence, with one exception: its view of the future. Until about 250 years ago, when yesterday began, the future was static; the present simply continued endlessly as there were no self-generating changes. The future alters with the arrival of capitalism, Western science and technology and popular political movements. Suddenly, endless progress becomes the main theme of the future. While the distant past continued for most of humanity, a new era appeared in the nations of the West. But faith in perpetual progress is now waning. Our trust in science and technology has been shaken. We are more sceptical about our political institutions and their ability to deliver a just and equitable society. Capitalism, we have learned, says Heilbroner, is only good for the rich. In the United States alone, the number of people living in poverty rose from 23 million to 35 million between 1975 and 1991, whereas the number of millionaires increased from 642 to 60,667 . So tomorrow demands that we re-examine our basic assumptions.

Whereas Heilbroner asks that we rethink our economic principles, political institutions and the nature of our science and technology, Gimpel argues for a new way of seeing technological development. The crisis in the West is largely due to our disenchantment with a host of technologies that were seen purely in utopian terms. Such notions as the 'electronic cottage', intelligent and perfect computers and space travel were seen as panaceas that would rescue humankind from its follies. Instead, they have turned out to be mirages. Indeed, we are going backwards into the future: concerned citizens are giving up their cars for bicycles, we increasingly prefer cotton, silk and linen to man-made fibres, and concrete is being abandoned in favour of timber-framed housing.

All this means that the West has reached a technological plateau. From now on, technologies may seem to be better, faster and more promising, but in reality they would not improve our lives, or deliver the greatest material benefits to most of humanity, or make us more happy. Moreover, we can already discern a marked decline in technological innovation. The belief in the power of technology to rescue our future is therefore dangerously obsolete.

The future is thus waiting to explode. We can no longer be sure, Heilbroner asserts, that we will actually survive. The only way to do so is to think more concretely and imaginatively about the future. In particular, we must focus our thinking about the future on three principles. First, we must ensure that we achieve a secure terrestrial base for life. This means abandoning many cherished notions about materialism, progress and perpetual advances in science and technology. Second, we must "find ways of preserving the human community as a whole against its warlike proclivities". This requires abandoning naked capitalism for more humane economics and seeking more appropriate models of governance. Third, the distant future must take us towards a much deeper and more abiding respect for 'human nature' and this can be ensured only if we make total respect for human dignity a prime focus in our contemporary cultural and educational concerns.

Gimpel does not offer a prescription for the future. He simply asserts that we have reached the end of the golden age of Western science and technology. And the West, like all other civilizations, as ibn Khaldun and others have predicted, must decline in order to rise again in some far distant future. The present phase of the cycle of rise and decline of civilizations favours the Asian civilizations. The near future, the twenty-first century, belongs to Asia in general and to China in particular. The centre of world trade has already moved to the Pacific Basin. The nations of the Far East are growing at a phenomenal annual rate of eight per cent - and there is no indication that this will slow down in the next decades. The growth of Asia means the end of 'white supremacy' and the return to a future of a thousand years ago. "China is at the beginning of a cycle that could last a millennium, while western civilization stands at the end of a cycle that is already 1,000 years old", says Gimpel. Who could argue with that?

Ziauddin Sardar, a consulting editor of Futures and visiting professor of science and technology policy at Middlesex University, is at 1 Orchard Gate, London NW9 6HE, UK. 